\title{
ON THE INVARIANCE EQUATION FOR HEINZ MEANS
}

\section{ÁDÁM BESENYEI}

Abstract. We solve the so-called invariance equation in the class of Heinz means, that is, we give necessary and sufficient conditions for the constants $0 \leqslant p, q, r \leqslant 1$ such that the identity

$$
H_{p}\left(H_{q}(x, y), H_{r}(x, y)\right)=H_{p}(x, y) \quad\left(x, y \in \mathbb{R}^{+}\right)
$$

holds true where the Heinz mean $H_{p}$ is defined for $0 \leqslant p \leqslant 1$ as

$$
H_{p}(x, y)=\frac{x^{p} y^{1-p}+x^{1-p} y^{p}}{2} .
$$

The Taylor expansion of the Heinz mean is used.

Mathematics subject classification (2010): 26E60.

Keywords and phrases: invariance equation, Gaussian mean iteration, Heinz mean.

\section{REFERENCES}

[1] K. M. R. AUDENAERT, In-betweenness, a geometrical operator monotonicity property for operator means, Linear Algebra Appl., in press, 2011.

[2] R. BHATIA, Interpolating the arithmetic-geometric mean inequality and its operator version, Linear Algebra Appl. 413 (2006), 355-363.

[3] J. M. Borwein AND P. B. Borwein, qit Pi and the AGM: A study in analytic number theory and computational complexity, John Wiley \& Sons Inc., New York, 1987.

[4] Sz. BAJÁK AND Zs. PÁLES, Computer aided solution of the invariance equation for two-variable Gini means, Comput. Math. Appl. 58 (2009), 334-340.

[5] SZ. BAJÁK AND Zs. PÁLES, Computer aided solution of the invariance equation for two-variable Stolarsky means, Appl. Math. Comput. 216, 11 (2010), 3219-3227.

[6] I. COSTIN AND G. TOADER, Invariance in the class of weighted Lehmer means, JIPAM. J. Inequal. Pure Appl. Math. 9, 2 (2008), Article 54.

[7] I. COSTIN AND S. TOADER, Complementariness with respect to the logarithmic mean, Math. Inequal. Appl. 12, 4 (2009), 791-798.

[8] Z. DARócZY AND Zs. PÁles, Gauss-composition of means and the solution of the Matkowski-Sutô problem, Publ. Math. Debrecen 61, 1-2 (2002), 157-218.

[9] H. W. Gould, Coefficient identities for powers of Taylor and Dirichlet series, Amer. Math. Monthly 81 (1974), 3-14.

[10] G. Hardy, J. E. Littlewood, G. Pólya, Inequalities, Cambridge Univ. Press, Cambridge, 1934.

[11] E. HeinZ, Beiträge zur Störungstheorie der Spektralzerlegung, Math. Ann. 123 (1951), 415-438.

[12] J. JARCZYK AND J. MATKOWS KI, Invariance in the class of weighted quasi-arithmetic means, Ann. Polon. Math. 88, 1 (2006), 39-51.

[13] J. MATKOWSKI, Invariant and complementary quasi-arithmetic means, Aequationes Math. 57, 1 (1999), 87-107.

[14] O. Sutô, Studies on some functional equations I, Tôhoku Math. J. 6 (1914), 1-15; II, Tôhoku Math. J. 6 (1914), 82-101.

[15] G. Toader And S. Toader, Greek Means and the Arithmetic-Geometric Mean, RGMIA Monographs, Victoria University, 2005.

[16] T. TRIF, Sharp inequalities involving the symmetric mean, Miskolc Math. Notes. 3 (2002), 157-164. 